\title{
Acute Reversible Myocardial Depression Associated with Sepsis
}

\author{
Makoto Kontani, Yoshiaki IzUMIYA*, Miho SHIMIZU*, Keiichi Yasuma, \\ Akira INADA*, Hajime OHTA** and Takayuki IKEDA
}

\begin{abstract}
A 30-year-old man was admitted to our hospital for left lobar pneumonia with septic shock. Acute left-sided heart failure became evident as sepsis developed. Echocardiography revealed diffuse severe hypokinesis of the left ventricle (LV) and a pulmonary artery catheter showed Forrester subset II hemodynamics. Along with amelioration of sepsis and decrease of the serum concentrations of tumor necrosis factor- $\alpha$ and interleukin- $6, \mathrm{LV}$ hypokinesis improved. It is suggested that the patient's heart failure may have been due to functional depression of myocardial contractility resulting from a direct effect of the cytokines towards the cardiomyocytes, the socalled "septic myocardial depression".

(Internal Medicine 42: 60-65, 2003)
\end{abstract}

Key words: sepsis, left ventricular failure, proinflammatory cytokines

\section{Introduction}

Sepsis is often accompanied by shock characterized by a high cardiac index and a low systemic vascular resistance (1, 2 ), the so-called "hyperdynamic shock". However, some patients with septic shock have the complication of congestive heart failure without any evidence of organic heart disease and they exhibit transient left ventricular systolic dysfunction that recovers along with amelioration of sepsis (3-5). This phenomenon is termed "septic myocardial depression (6)" or "acute septic cardiomyopathy (7)". We describe a patient who developed severe transient myocardial depression associated with sepsis caused by pneumonia.

\section{Case Report}

A 30-year-old man was admitted to our hospital on April 15,2001 , with high fever, left sided chest pain and dyspnea. His past medical history was significant for ulcerative colitis which had responded well to treatment with oral prednisolone and mesalazine. Several days prior to admission, he had a sore throat with a non-productive cough and was treated with oral antibiotics and non-steroidal antiinflammatory agents.

On admission, he was fully conscious. His temperature was $38.7^{\circ} \mathrm{C}$, with a blood pressure (BP) of $60 / 30 \mathrm{mmHg}$ and pulse rate of $130 / \mathrm{min}$. His skin was warm and moist but not cyanotic. No heart murmur, crackles or rubs were audible over his chest, but he had mild knocking pain on his left lateral chest. No abnormal findings were observed in the abdomen. Laboratory data showed elevated inflammatory

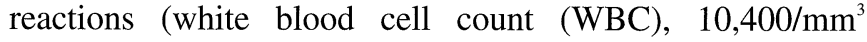
(neutrophils, $71.5 \%$ ); C-reactive protein (CRP), $5.8 \mathrm{mg} / \mathrm{dl}$ ) and hypoxia. Other laboratory values included the following: hemoglobin, $15.0 \mathrm{~g} / \mathrm{dl}$; hematocrit, 44.6\%; platelet, 23.0x $10^{4} / \mathrm{mm}^{3}$; serum urea nitrogen, $14.1 \mathrm{mg} / \mathrm{dl}$; serum creatinine, $1.1 \mathrm{mg} / \mathrm{dl}$; sodium, $136 \mathrm{mEq} / l$; potassium, $3.1 \mathrm{mEq} / l$; aspartate aminotransferase, $30 \mathrm{IU} / l$; alanine aminotransferase, 27 $\mathrm{IU} / l$; lactate dehydrogenase, $406 \mathrm{IU} / l$; amylase $58 \mathrm{IU} / l$; and total protein, $6.1 \mathrm{~g} / \mathrm{dl}$. Arterial blood gas while breathing room air showed the following: $\mathrm{pH}, 7.427 ; \mathrm{pO}_{2}, 43.4$ Torr; $\mathrm{pCO}_{2}, 36.3$ Torr; $\mathrm{HCO}_{3}, 23.9 \mathrm{mEq} / l$; base excess, $0.6 \mathrm{mEq} /$ $l$; and $\mathrm{O}_{2}$ saturation, $80.7 \%$. Chest $\mathrm{X}$-ray showed no apparent abnormal finding, but computed tomography revealed a consolidative shadow in the left lower lobe of the lung (Fig. 1, upper panels). Electrocardiogram (ECG) revealed sinus tachycardia.

The diagnosis of left lobar pneumonia with septic shock was made and then treatment with inhaled $\mathrm{O}_{2}$ at 7 liter/min, intravenous fluid, steroid pulse therapy (methylprednisolone $1,000 \mathrm{mg} /$ day) and antibiotics (meropenem $0.5 \mathrm{~g} /$ day and

From the Department of Cardiology, *the Department of Internal Medicine and **the Department of Gastroenterology, Tsuruga Municipal Hospital, Fukui Received for publication March 18, 2002; Accepted for publication December 5, 2002

Reprint requests should be addressed to Dr. Makoto Kontani, the Department of Cardiology, Tsuruga Municipal Hospital, 1-6-60 Mishima-cho, Tsuruga, Fukui 914-8502 
Day 1
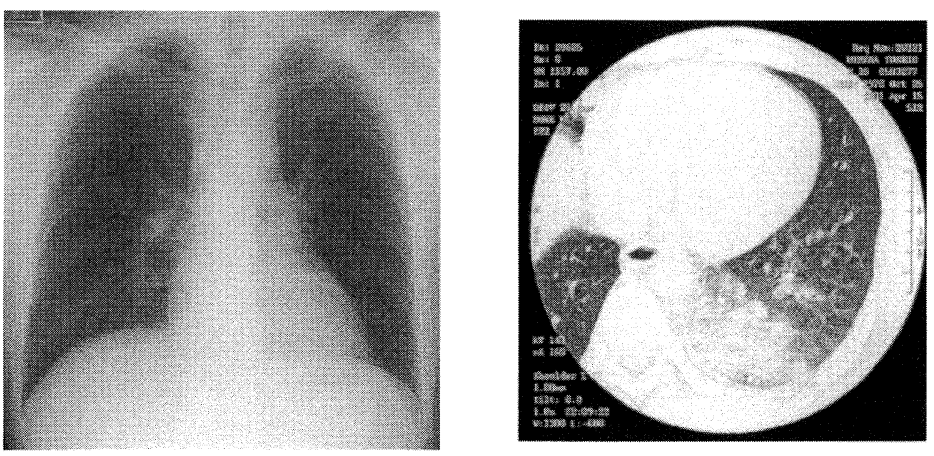

Day 2

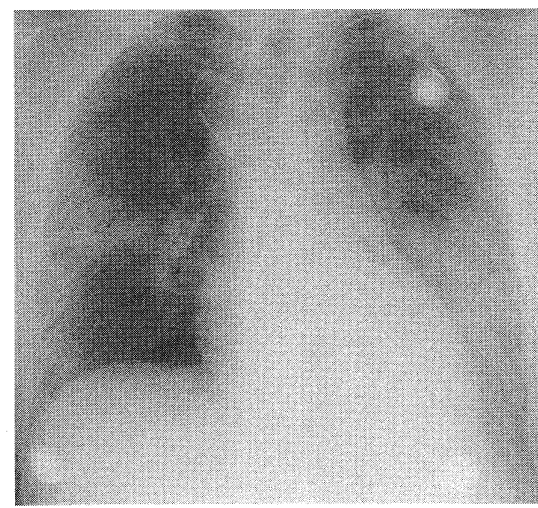

Day 4

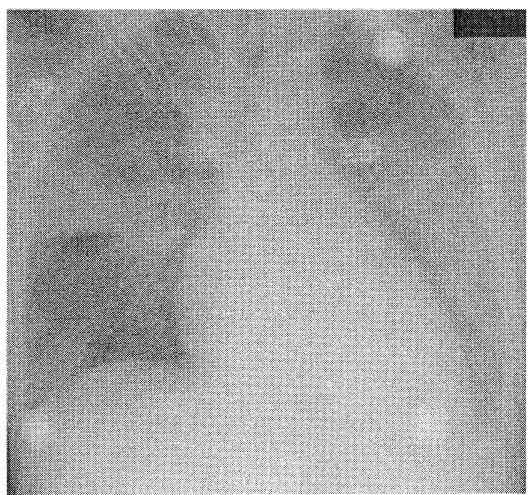

Day 5

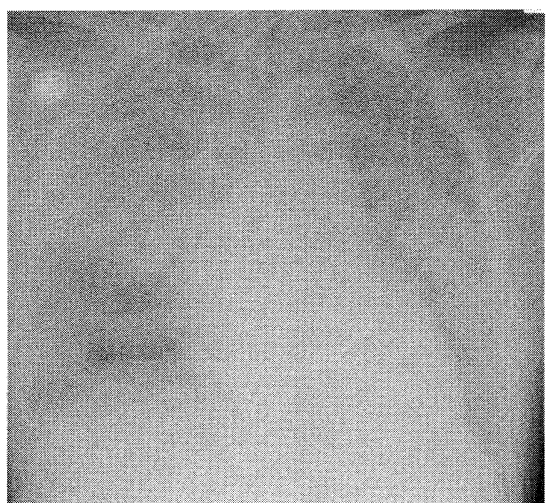

Figure 1. Chest X-ray and computed tomography on admission (upper panels) and chest X-rays during hospitalization (lower panels).

erythromycin $1,000 \mathrm{mg} /$ day) was started. However, oxygenation was not sufficient and dyspnea and confusion developed. On the second hospital day, he was intubated and required mechanical ventilation and central venous catheterization. Central venous pressure was $9 \mathrm{cmH}_{2} \mathrm{O}$. Dopamine and dobutamine were given and his BP rose to $90 \mathrm{mmHg}$. On the third hospital day, CRP elevated to $46.1 \mathrm{mg} / \mathrm{dl}$ and WBC severely decreased. Laboratory data showed multiorgan damage (Tables 1, 2). Endotoxin absorption and continuous venovenous hemodiafiltration (CHDF) were performed and clindamycin 1,200 mg/day and amphotericin B $30 \mathrm{mg} /$ day were added. However, chest X-ray showed progressive deterioration with cardiomegaly and bilateral pleural effusion along with the appearance of consolidative shadow in the right lung. (Fig. 1, lower panels).

Echocardiography on the fifth hospital day revealed severe diffuse hypokinesis of left ventricle (LV) (Fig. 2, left panel), and Swan-Ganz catheter demonstrated a mean pulmonary artery wedge pressure of $25 \mathrm{mmHg}$ and cardiac index of $3.0 \mathrm{l} / \mathrm{min} \cdot \mathrm{m}^{2}$, Forrester subset II. Olprinone hydrochloride, PDE-III inhibitor, $0.15 \mu \mathrm{g} / \mathrm{kg} \cdot \mathrm{min}$ was started, and his hemodynamic status immediately improved to Forrester subset I (Fig. 3). Thereafter, the patient's condition gradually improved, but the causative organism for pneumonia and sepsis was not identified despite extensive investigations for Legionella pneumophilia, Mycobacteria, Mycoplasma, fungi, Chlamydias, and viruses. Serum $\beta$-D-glucan before CHDF was elevated $(165.9 \mathrm{pg} / \mathrm{ml})$, suggesting that there might have been a fungal infection, but endotoxin was negative. On the seventh hospital day, when his hemodynamic status was in Forrester subset I, echocardiography still showed diffuse hypokinesis of LV. However, on the 32nd hospital day, when all the instrumentations, inotropic agents and antibiotics had been withdrawn, LV ejection fraction (LVEF) had improved to $63 \%$ and LV end-diastolic dimension had decreased to $46 \mathrm{~mm}$ (Fig. 2, middle and right panels). There was no significant ECG change during hospitalization and laboratory data did not reveal definite evidence of myocardial injury (Table 2). Radioisotope imaging showed normal myocardial perfusion and fatty acid metabolism. Cardiac catheterization performed on the 44th hospital day revealed no organic abnormalities of the heart; coronary arteriogram showed no significant epicardial coronary artery stenosis, left ventriculogram showed normal LV wall motion with LVEF of $78 \%$, Swan-Ganz catheter demonstrated a mean pulmonary artery wedge pressure of $4 \mathrm{mmHg}$ and cardiac index of $4.6 \mathrm{l} / \mathrm{min} \cdot \mathrm{m}^{2}$, and myocardial biopsy of right ventricular septum revealed no evidence of myocardial 
Table 1. Laboratory Data on Hospital Day 3

\begin{tabular}{|c|c|c|}
\hline White blood cell count & $1,800 / \mathrm{mm}^{3}$ & $(3,500-8,000)$ \\
\hline Neutrophils & $46.2 \%$ & $(30.0-80.0)$ \\
\hline Lymphocytes & $42.9 \%$ & $(15.0-60.0)$ \\
\hline Eosinophils & $1.6 \%$ & $(0.0-10.0)$ \\
\hline Basophils & $3.8 \%$ & $(0.0-2.0)$ \\
\hline Monocytes & $5.5 \%$ & $(1.0-10.0)$ \\
\hline Red blood cell count & $492 \times 10^{4} / \mathrm{mm}^{3}$ & $(450-550)$ \\
\hline Hemoglobin & $15.4 \mathrm{~g} / \mathrm{dl}$ & $(14.0-16.0)$ \\
\hline Hematocrit & $43.7 \%$ & $(40.0-50.0)$ \\
\hline Platelet & $21.4 \times 10^{4} / \mathrm{mm}^{3}$ & $(15.0-40.0)$ \\
\hline Total protein & $5.3 \mathrm{~g} / \mathrm{dl}$ & $(6.5-8.3)$ \\
\hline Albumin & $2.4 \mathrm{~g} / \mathrm{dl}$ & $(3.5-4.8)$ \\
\hline Aspartate aminotransferase & $146 \mathrm{IU} / l$ & $(10-40)$ \\
\hline Alanine aminotransferase & $43 \mathrm{IU} / l$ & $(5-35)$ \\
\hline Alkaline phosphatase & $124 \mathrm{IU} / l$ & $(104-338)$ \\
\hline$\gamma$-Glutamyltranspeptidase & $38 \mathrm{IU} / l$ & $(0-70)$ \\
\hline Amylase & $54 \mathrm{IU} / l$ & $(40-160)$ \\
\hline Blood urea nitrogen & $33.5 \mathrm{mg} / \mathrm{dl}$ & $(8.0-20.0)$ \\
\hline Creatinine & $3.1 \mathrm{mg} / \mathrm{dl}$ & $(0.6-1.3)$ \\
\hline $\mathrm{Na}$ & $132 \mathrm{mEq} / \mathrm{l}$ & $(135-147)$ \\
\hline $\mathrm{K}$ & $4.3 \mathrm{mEq} / \mathrm{l}$ & $(3.6-4.8)$ \\
\hline $\mathrm{Cl}$ & $98 \mathrm{mEq} / \mathrm{l}$ & $(98-108)$ \\
\hline Creatine kinase & $3,928 \mathrm{IU} / l$ & $(50-230)$ \\
\hline MB isozyme of creatine kinase & $8.5 \mathrm{ng} / \mathrm{ml}$ & $(<7.5)$ \\
\hline C-reactive protein & $46.1 \mathrm{mg} / \mathrm{dl}$ & $(0.0-0.4)$ \\
\hline
\end{tabular}

*Values within ( ) show our institutional reference ranges.
Table 2. More Laboratory Data on Hospital Day 3 (continued)

$\begin{array}{lll}\text { Arterial Blood Gas Analysis (Pressure support, } \mathrm{FIO}_{2} & 80 \%) \\ \mathrm{pH} & 7.394 & (7.38-7.46) \\ \mathrm{pO}_{2} & 104.2 \mathrm{Torr} & (84-108) \\ \mathrm{pCO}_{2} & 23.4 \mathrm{Torr} & (32-46) \\ \mathrm{HCO}_{3} & 14.3 \mathrm{mEq} / l & (21-29) \\ \mathrm{Base} \text { excess } & -7.9 \mathrm{mEq} / l & (-2-2) \\ \mathrm{O}_{2} \text { saturation } & 97.9 \% & \\ & & \\ \text { Fasting Blood Glucose } & 153 \mathrm{mg} / \mathrm{dl} & (70-110) \\ & & \\ \text { Fibrinogen } & 650 \mathrm{mg} / \mathrm{dl} & (170-390) \\ \text { Prothrombin time } & 18.0 \mathrm{~seconds} & (10.0-15.0) \\ \text { Activated partial thromboplastin time } & 44.9 \mathrm{~seconds} & (24.0-34.0) \\ \text { Fibrin/fibrinogen degradation products } & 16.5 \mathrm{\mu g} / \mathrm{ml} & (0.0-10.0) \\ \text { (FDP) } & & \\ \text { FDP-D dimer } & 8.4 \mathrm{ng} / \mathrm{ml} & (0.0-0.9) \\ & & \\ \text { Myosin light chain I } & 21.2 \mathrm{ng} / \mathrm{ml} & (<2.5) \\ \text { Troponin T } & 0.01 \mathrm{ng} / \mathrm{ml} & (<0.10) \\ & & \\ \alpha \text {-atrial natriuretic peptide } & 77.9 \mathrm{pg} / \mathrm{ml} & (<43.0) \\ \text { B-type natriuretic peptide } & 1,364.4 \mathrm{pg} / \mathrm{ml}(<18.4) & \\ & & \end{array}$

Day 5

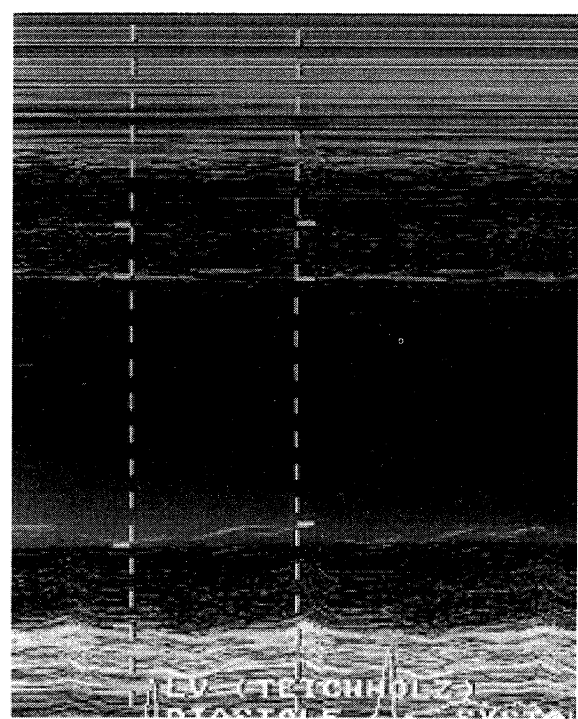

$\begin{array}{ll}\text { LVEF (\%) } & 15 \\ \text { LVEDD (mm) } & 48\end{array}$
Day 7

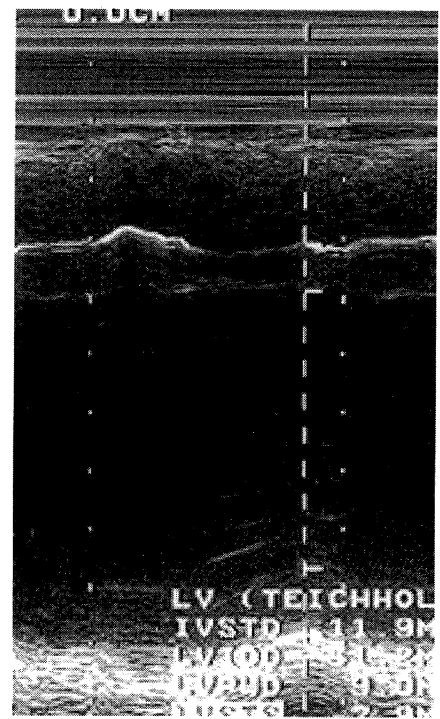

14

51
Day 32

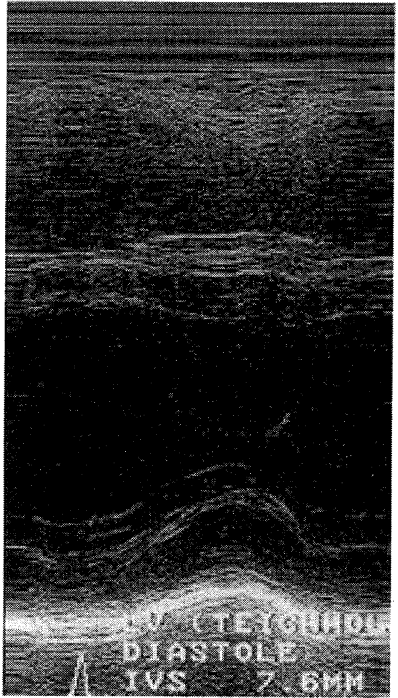

63

46

Figure 2. Changes in echocardiographic findings (LVEDD, left ventricular end-diastolic dimension; LVEF, left ventricular ejection fraction). 


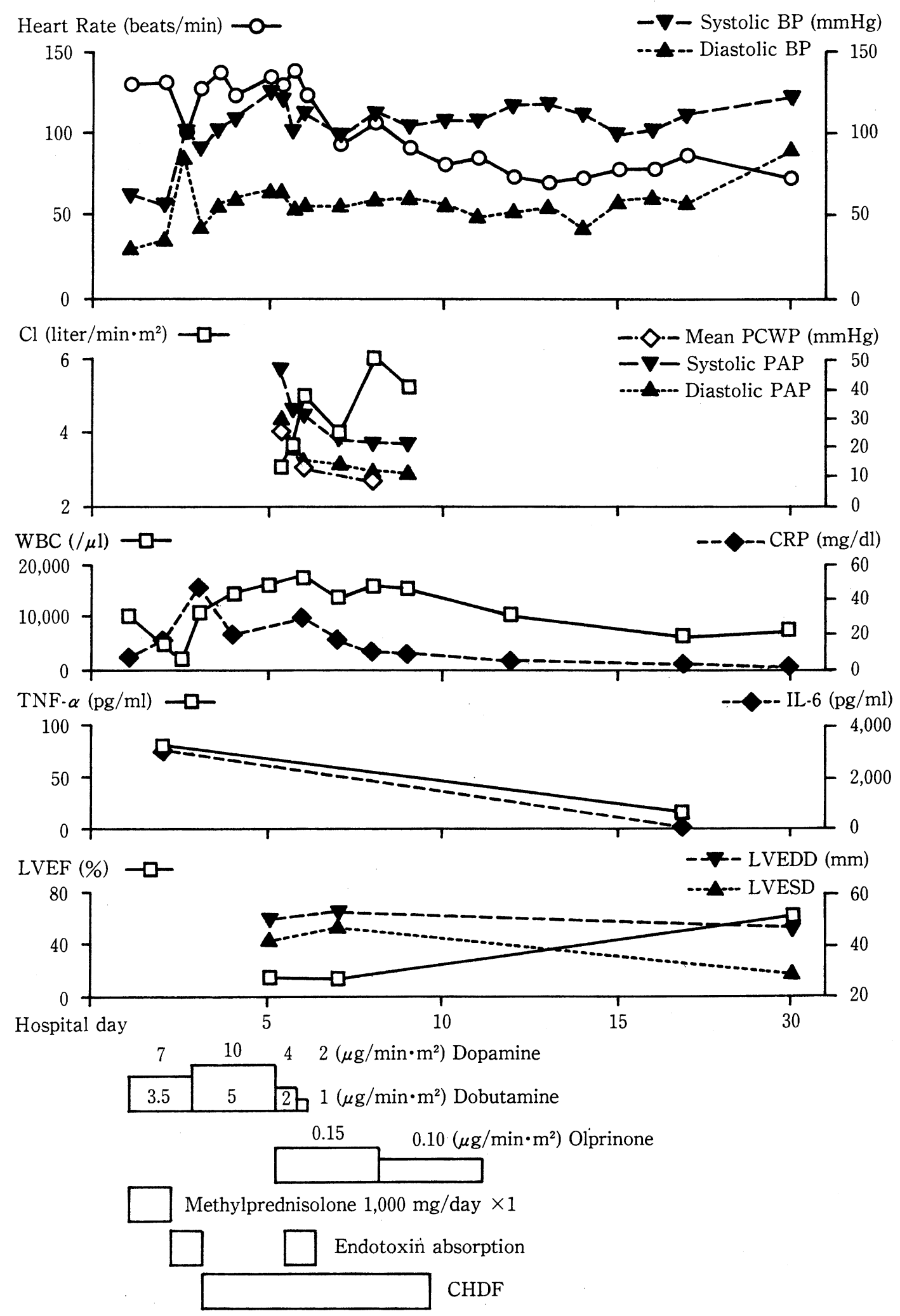

Figure 3. Schematic presentation of the clinical course of this case (BP, blood pressure; CHDF, continuous hemodiafiltration; CI, cardiac index; CRP, C-reactive protein; IL-6, interleukin-6; LVESD, left ventricular endsystolic dimension; PAP, pulmonary arterial pressure; PCWP, pulmonary capillary wedge pressure; TNF- $\alpha$, tumor necrosis factor- $\alpha$; WBC, white blood cell count). 


\section{KONTANI et al}

inflammation, abnormal substance deposition, or granuloma formation.

Serum concentrations of tumor necrosis factor- $\alpha$ (TNF- $\alpha$ ) and interleukin-6 (IL-6) were markedly elevated $(83 \mathrm{pg} / \mathrm{ml}$ and $3,040 \mathrm{pg} / \mathrm{ml}$, respectively). And along with the amelioration of the patient's inflammation and cardiac function, both values of these cytokines fell beneath the reference level (Fig. 3). However, the serum concentration of IL-1 $\beta$ was not elevated (less than $8 \mathrm{pg} / \mathrm{ml}$ ) in either the acute or convalescent phase. The patient made a full recovery and was discharged without sequelae on the 56th hospital day.

\section{Discussion}

Septic shock is a common and serious disorder and its hemodynamics are characterized by a high cardiac index and a low systemic vascular resistance $(1,2)$, the so-called "hy perdynamic shock". However, it also has been reported that some patients with septic shock exhibit a transient depression of cardiac contractility and make rapid recovery along with amelioration of sepsis (3-5). This condition has been termed "septic myocardial depression (6)" or "acute septic cardiomyopathy (7)". Endotoxin $(8,9)$, TNF- $\alpha$ (9) and IL$1 \beta$ (10) have been reported to induce the same hemodynamic changes as seen in the clinical settings; hypotension and decrease in cardiac output, systemic vascular resistance and $\operatorname{LVEF}(8,9)$. Experimental studies $(6,7,10,11)$ have shown that proinflammatory cytokines such as TNF- $\alpha(6,7,10,11)$ and $\operatorname{IL}-1 \beta(6,7,10)$ induce a negative inotropic effect through nitric oxide (NO)-dependent $(6,10)$ or NO-independent $(6,7,10,11)$ mechanisms; TNF- $\alpha$ is reported to exert its myocardial depressant effects by activation of myocardial constitutive NO synthase (cNOS) and gene expression of inducible NOS (iNOS) leading to increased NO production. It also activates the sphingomyelin pathway leading to sphingosine production, which blocks the ryanodine receptor on the sarcoplasmic reticulum to impede $\mathrm{Ca}^{2+}$-induced $\mathrm{Ca}^{2+}$ release $(6,10,12)$. IL- 6 production is activated by both TNF- $\alpha$ and IL- $1 \beta$ and also has a negative inotropic effect through an NO-dependent pathway (11).

In the present case, the serum concentrations of some proinflammatory cytokines were markedly elevated when the patient had sepsis and acute left-sided heart failure, but there was no evidence of any cardiac disease or extracardiac conditions to induce acute left ventricular systolic dysfunction. Laboratory data suggesting myocardial injury such as elevated serum levels of troponin $\mathrm{T}$ were not obtained. Although the levels of creatine kinase, MB isozyme of creatine kinase and myosin light chain 1(MLC1) were elevated, these biological markers are known to be elevated in patients with skeletal muscle injury. Radioimmunoassay system of MLC1 is known to partially cross-react with skeletal muscle MLC (13). There was no ECG change throughout entire period of hospitalization, even in the acute phase, also indicating that myocardial ischemia and/or injury were not present. Furthermore, cardiac catheterization confirmed that there was no significant epicardial coronary artery stenosis and no evidence of organic myocardial injury suggesting myocarditis or specific cardiomyopathies in the biopsy specimen.

As mentioned earlier, endotoxin might have caused a transient LV systolic dysfunction $(8,9)$, but both endotoxin itself and endotoxin-producing bacteria were not detected from the sera of this patient. As a consequence, it was suggested that this patient's heart failure might have been due to functional depression of myocardial contractility resulting from a direct effect of the cytokines towards the cardiomyocytes, a pathophysiologic state compatible with the so-called "septic myocardial depression".

In contrast to the levels of TNF- $\alpha$ and IL- 6 , serum IL- $1 \beta$ levels were not elevated in this case. TNF- $\alpha$ and IL- $1 \beta$ have similar biological properties and often act synergistically (10) , but clinical studies which have examined the serum levels of these proinflammatory cytokines during septic shock have constantly shown a lack of elevation of serum IL-1 $\beta$ concentration despite a concomitant increased level of TNF- $\alpha(14,15)$. These findings suggest that one cannot ascertain whether IL- $1 \beta$ plays a role in the pathogenesis of septic myocardial depression in the clinical setting on the basis of serum IL- $1 \beta$ concentration alone. On the other hand, the concentrations of the other cytokines TNF- $\alpha$ and IL- 6 have been shown to be related to the severity of sepsis and prognosis of the patients with sepsis and/or septic shock $(14,15)$. This may reflect the pathophysiologic relation between these cytokines and "septic myocardial depression" previously shown in many experimental studies $(6-10,11)$.

In spite of these well-known experimental data, clinical case reports on this condition are few (5). The reason for this may be in part because these phenomena are not well recognized by many clinicians dedicated to critical care and efforts to further clarify the other etiologies of shock in such septic patients are not often made. However, as Parker et al reported (3), this condition is not rare in patients with sepsis. The present case suggests the importance to recognize that "septic myocardial depression" should be kept in mind when one sees septic patients with congestive heart failure, especially those with acute left-sided failure.

\section{References}

1) Winslow EJ, Loeb HS, Rahimtoola SH, Kamath S, Gunnar RM. Hemodynamic studies and results of therapy in 50 patients with bacteremic shock. Am J Med 54: 421-432, 1973.

2) Wilson RF, Thal AP, Kindling PH, Grifka T, Ackerman E. Hemodynamic measurements in septic shock. Arch Surg 91: 121-129, 1965.

3) Parker MM, Shelhamer JH, Bacharach SL, et al. Profound but reversible myocardial depression in patients with septic shock. Ann Intern Med 100: 483-490, 1984.

4) Parrillo JE. Pathogenetic mechanisms of septic shock. [see comments] N Engl J Med 328: 1471-1477, 1993.

5) Iwasaki M, Tamura $T$, Hikosaka $M$, et al. Acute left ventricular failure associated with sepsis. Shinzo 32: 721-726, 2000 (in Japanese).

6) Kumar A, Kumar A, Parrillo JE. Cytokines and septic myocardial depression: nitric oxide versus sphingosine/ceramide? [editorial; 


\section{Septic Myocardial Depression}

comment] Crit Care Med 27: 1391-1393, 1999.

7) Muller-Werdan U, Schumann H, Fuchs R, et al. Tumor necrosis factor$\alpha$ (TNF- $\alpha$ ) is cardiodepressant in pathophysiologically relevant concentrations without inducing inducible nitric oxide (NO)-synthase (iNOS) or triggering serious cytotoxicity. J Mol Cell Cardiol 29: 29152923, 1997.

8) Suffredini AF, Fromm RE, Parker MM, et al. The cardiovascular response of normal humans to the administration of endotoxin. [see comments] N Engl J Med 321: 280-287, 1989.

9) Natanson C, Eichenholz PW, Danner RL, et al. Endotoxin and tumor necrosis factor challenges in dogs simulate the cardiovascular profile of human septic shock. J Exp Med 169: 823-832, 1989.

10) Cain BS, Meldrum DR, Dinarello CA, et al. Tumor necrosis factor- $\alpha$ and interleukin $-1 \beta$ synergistically depress human myocardial function. [see comments] Crit Care Med 27: 1309-1318, 1999.

11) Sugishita $K$, Kinugawa $K$, Shimizu T, et al. Cellular basis for the acute inhibitory effects of IL- 6 and TNF- $\alpha$ on excitation-contraction coupling. J Mol Cell Cardiol 31: 1457-1467, 1999.

12) Dettbarn CA, Betto R, Salviati G, Palade P, Jenkins GM, Sabbadini RA. Modulation of cardiac sarcoplasmic reticulum ryanodine receptor by sphingosine. J Mol Cell Cardiol 26: 229-242, 1994.

13) Fukunaga H, Higuchi I, Usuki F, Moritoyo T, Okubo R. Clinical significance of serum cardiac myosin light chain $\mathrm{I}$ in patients with Duchenne muscular dystrophy. No To Shinkei 44: 131-135, 1992 (in Japanese, Abstract in English).

14) Damas P, Ledoux D, Nys $M$, et al. Cytokine serum level during severe sepsis in human IL-6 as a marker of severity. Ann Surg 215: 356-362, 1992.

15) Riche FC, Cholley BP, Panis YH, et al. Inflammatory cytokine response in patients with septic shock secondary to generalized peritonitis. Crit Care Med 28: 433-437, 2000. 